Article

\title{
miR-25-3p, Positively Regulated by Transcription Factor AP-2 $\alpha$, Regulates the Metabolism of C2C12 Cells by Targeting Akt1
}

\author{
Feng Zhang ${ }^{1,2}$, Kun Chen ${ }^{2}$, Hu Tao ${ }^{1}$, Tingting Kang ${ }^{2}$, Qi Xiong ${ }^{1}$, Qianhui Zeng ${ }^{2}$, Yang Liu ${ }^{1}$, \\ Siwen Jiang ${ }^{2, *}$ and Mingxin Chen ${ }^{1, *}$ \\ 1 Hubei Key Laboratory of Animal Embryo Engineering and Molecular Breeding, Institute of Animal \\ Husbandry and Veterinary, Hubei Academy of Agricultural Sciences, Wuhan 430064, China; \\ zhangfeng0130@163.com (F.Z.); taohu00@gmail.com (H.T.); phenixxq@163.com (Q.X.); \\ liuyang430209@163.com (Y.L.) \\ 2 Key Laboratory of Swine Genetics and Breeding of the Agricultural Ministry and Key Laboratory of \\ Agricultural Animal Genetics, Breeding and Reproduction of the Ministry of Education, \\ College of Animal Science and Technology, Huazhong Agricultural University, Wuhan 430070, China; \\ kunchen1989@163.com (K.C.); 13163228175@126.com (T.K.); \\ zengqianhui.hzau.cn@webmail.hzau.edu.cn (Q.Z.) \\ * Correspondence: jiangsiwen@mail.hzau.edu.cn (S.J.); chenmingxin18@163.com (M.C.); \\ Tel.: +86+027-8728-1378 (S.J.); +86+027-8768-0959 (M.C.)
}

Received: 15 January 2018; Accepted: 6 March 2018; Published: 8 March 2018

\begin{abstract}
R-25, a member of the miR-106b-25 cluster, has been reported as playing an important role in many biological processes by numerous studies, while the role of miR-25 in metabolism and its transcriptional regulation mechanism remain unclear. In this study, gain-of-function and loss-of-function assays demonstrated that miR-25-3p positively regulated the metabolism of C2C12 cells by attenuating phosphoinositide 3-kinase (PI3K) gene expression and triglyceride (TG) content, and enhancing the content of adenosine triphosphate (ATP) and reactive oxygen species (ROS). Furthermore, the results from bioinformatics analysis, dual luciferase assay, site-directed mutagenesis, qRT-PCR, and Western blotting demonstrated that miR-25-3p directly targeted the AKT serine/threonine kinase 1 (Akt1) $3^{\prime}$ untranslated region ( $3^{\prime} \mathrm{UTR}$ ). The core promoter of miR-25-3p was identified, and the transcription factor activator protein- $2 \alpha(\mathrm{AP}-2 \alpha)$ significantly increased the expression of mature miR-25-3p by binding to its core promoter in vivo, as indicated by the chromatin immunoprecipitation (ChIP) assay, and AP-2 $\alpha$ binding also downregulated the expression of Akt1. Taken together, our findings suggest that miR-25-3p, positively regulated by the transcription factor $\mathrm{AP}-2 \alpha$, enhances $\mathrm{C} 2 \mathrm{C} 12$ cell metabolism by targeting the Akt1 gene.
\end{abstract}

Keywords: mouse; miR-25-3p; Akt1; AP-2 $\alpha$; promoter; cell metabolism

\section{Introduction}

MicroRNAs (miRNAs) are endogenous, small ( 22 nucleotides), and single-stranded noncoding RNAs. The role of different miRNAs in biological systems is well established. They are generally regarded as negative regulators of gene expression, as they bind to the $3^{\prime}$ untranslated region ( $3^{\prime} \mathrm{UTR}$ ) of messengerRNAs (mRNAs), leading to mRNA degradation and/or suppression of mRNA translation [1-3]. Currently, thousands of miRNAs have been identified as participating in a number of biological processes, such as cellular growth, proliferation, development, and metabolism [4].

Based on Solexa sequencing, the expression of microRNA-25 (miR-25) was higher in the longissimus dorsi muscle of Large White pigs (a lean type) than in those of Tongcheng pigs (a Chinese 
indigenous fatty pig). Because skeletal muscle plays a vital role in whole-body metabolism [5], we speculated that miR-25 could play a regulatory role in metabolism.

Previous studies have reported that miR-25 plays an important role in many biological processes. The expression of miR-25-3p was significantly increased in the plasma of thyroid papillary carcinoma, as compared with patients with benign tumors or healthy individuals [6]. miR-25 expression was higher in ovarian epithelial tissue, gastric cancer, lung adenocarcinoma, and many other tumors, and miR-25 expression levels were also closely related to tumor stage and lymph node metastasis [7-10]. Inhibition of miR-25 markedly improved cardiac contractility in the failing heart [11]. miR-25 could protect cardiomyocytes against oxidative damage by downregulating the mitochondrial calcium uniporter (MCU) [12]. Variations in miR-25 expression influenced the severity of diabetic kidney disease [13]. However, to our knowledge, the role of miR-25 in metabolism has not been reported, and its transcriptional regulatory mechanism is not clear.

Thus, in this study, we first investigated whether miR-25 was involved in metabolism by gain-of-function and loss-of-function assays. Then, the target gene of miR-25, AKT serine/threonine kinase 1 (Akt1), which is related to metabolism, was predicted and verified using bioinformatics software and experiments. Finally, the core promoter of miR-25 was identified, and the binding of the transcription factor activator protein- $2 \alpha(\mathrm{AP}-2 \alpha)$ to the core promoter was shown to promote the transcriptional activity of miR-25 and downregulate Akt1 expression.

\section{Results}

\section{1. miR-25 Is Highly Conserved in Mammals}

Clustal Omega (Available online: https:/ /www.ebi.ac.uk/Tools/msa/clustalo/) [14] was used to build the phylogenetic tree of pre-miRNA of miR-25. The results show that compared with other species selected in this study, the genetic relationship between mice and humans, cattle and goats, and gorillas and rhesus monkeys is closer (Figure 1A). The mature sequences of miR-25 are highly conserved in mammals, including pigs, mice, humans, goats, rats, hamsters, gorillas, chimpanzees, cattle, and rhesus monkeys. The "seed" sequences of miR-25 are identical, although there is a base deletion at the end of the chimpanzee sequence (ptr) (Figure 1B).

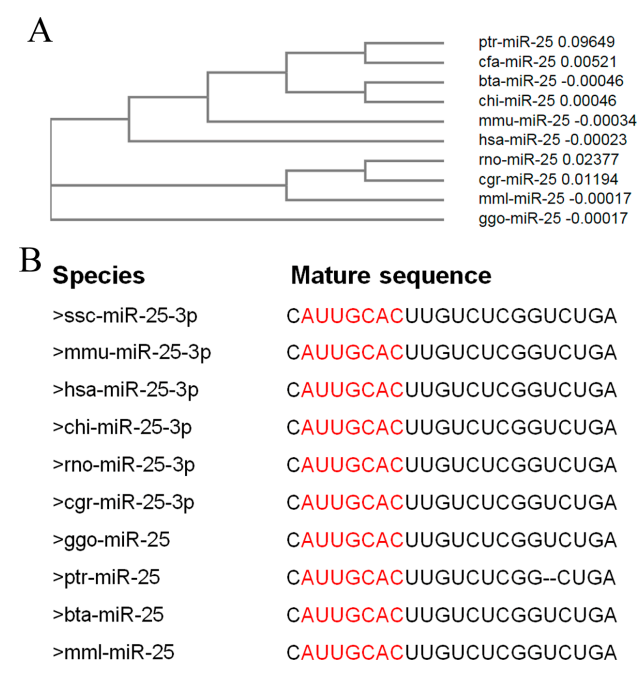

Figure 1. miR-25 is highly conserved in mammals. (A) The phylogenetic tree of pre-miRNA of miR-25. pre-miRNA sequences were obtained from NCBI. (B) The mature sequences of miR-25 in selected species. These mature sequences were obtained from miRBase. Seed regions are highlighted in red. ssc, sus scrofa; mmu, mus musculus; hsa, homo sapiens; chi, capra hircus; rno, rattus norvegicus; cgr, cricetulus griseus; ggo, gorilla gorilla; ptr, pan troglodytes; bta, bos taurus; mml, macaca mulatta; cfa, canis lupus familiaris. 


\subsection{Effects of miR-25 on the Metabolism of $\mathrm{C} 2 \mathrm{C} 12$ Cells}

To investigate the role of miR-25-3p in metabolism, miR-25-3p mimics/negative control (NC) or inhibitors/NC were respectively transfected into growing $\mathrm{C} 2 \mathrm{C} 12$ cells (mouse muscle myoblasts). The abundance of miR-25-3p was detected, which was $\sim 3300$-fold $(p<0.01)$ higher as compared with another microRNA (Figure S1). The mRNA and protein expression levels of the metabolism-related gene PI3K were repressed by miR-25-3p overexpression, while the levels of PI3K were upregulated in the inhibitor group, as compared with the negative controls (Figure 2A,B).

In addition, the overexpression of miR-25-3p decreased levels of triglyceride (TG), whereas the knockdown of miR-25-3p increased them (Figure 2C). Conversely, the overexpression of miR-25-3p increased ATP and ROS levels, and the knockdown of miR-25-3p decreased their levels (Figure 2D,E).These data indicate that miR-25-3p plays a role in metabolism.
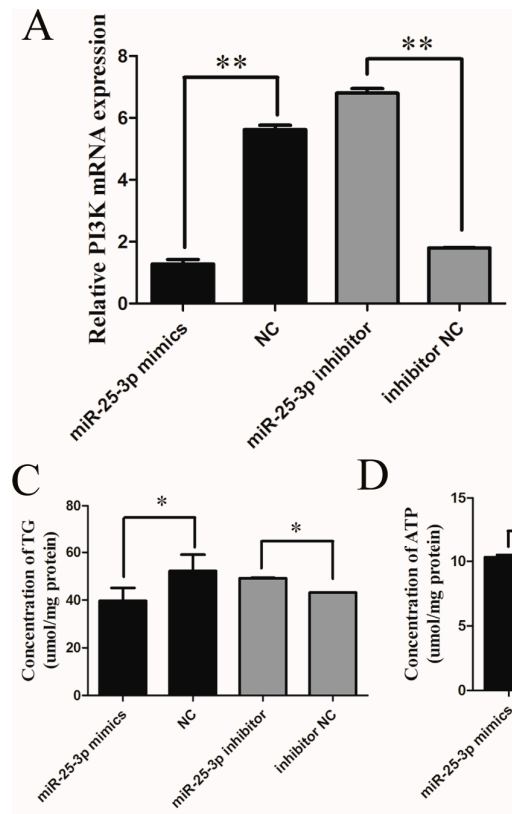

B

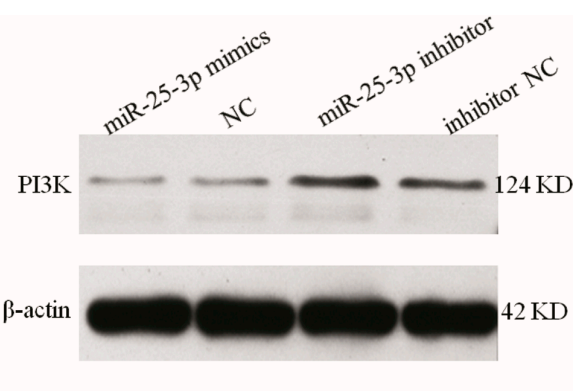

E

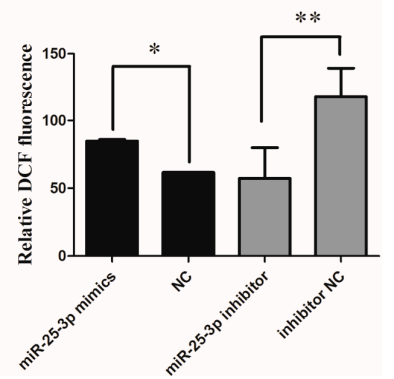

Figure 2. The effect of miR-25 on the metabolism of $\mathrm{C} 2 \mathrm{C} 12$ cells. miR-25-3p mimics/NC or inhibitors/NC were respectively transfected into growing $\mathrm{C} 2 \mathrm{C} 12$ cells. After $48 \mathrm{~h}$, PI3K expression was detected by qRT-PCR (A) and Western blotting (B). After 24-48 h transfection, the levels of triglyceride (TG) (C), ATP (D), and reactive oxygen species (ROS) (E) were measured with commercial kits. The fluorescence of DCF represents the content of ROS. NC = negative control (miR-239b-5p of caenorhabditis elegans). $\beta$-actin served as the loading control. Data were presented as means $\pm \mathrm{SD}$ $(n \geq 3) ;{ }^{*} p<0.05 ; * * p<0.01$.

\section{3. miR-25-3p Directly Targets Akt1}

To explore the molecular mechanism of miR-25-3p effects on metabolism, the possible targets for miR-25-3p were predicted using TargetScan, and a putative binding site for miR-25-3p was predicted in the $3^{\prime}$ UTR of $A k t 1$ mRNA. miR-25-3p targeting elements in the $A k t 1-3^{\prime}$ UTR were relatively conserved in many mammals, including mice, humans, chimpanzees, rhesus monkeys, and rats (Figure 3A).

To validate whether miR-25-3p directly targets $A k t 1$, a luciferase reporter containing a $250 \mathrm{bp}$ fragment from the $A k t 13^{\prime}$ UTR was tested in vitro. Additionally, we generated a mutated version of the above mentioned reporter, in which five nucleotides of the predicted binding site were changed in order to abolish the putative interaction between miR-25-3p and Akt1 mRNA (Figure 3B). The Akt1 $3^{\prime}$ UTR and mutant luciferase plasmid were cotransfected with mimics or NC into growing C2C12 cells. Twenty-four hours after transfection, analyses of luciferase activity revealed that miR-25-3p mimics significantly decreased the luciferase activity of the wild reporter plasmid as compared with 
NC, while there was no significant effect on the mutant plasmids (Figure 3C). These results revealed that miR-25-3p directly targets the 3'UTR of $A k t 1$ in vitro.

To directly test the validity of the putative target, we transfected miR-25-3p mimics and miR-25-3p inhibitors into growing $\mathrm{C} 2 \mathrm{C} 12$ cells. We found that the overexpression of miR-25-3p repressed Akt1 expression, as measured by qRT-PCR $(p<0.01)$ and Western blotting, whereas the knockdown of miR-25-3p derepressed it (Figure 3D,E). These results demonstrate that $A k t 1$ was a target of miR-25-3p.

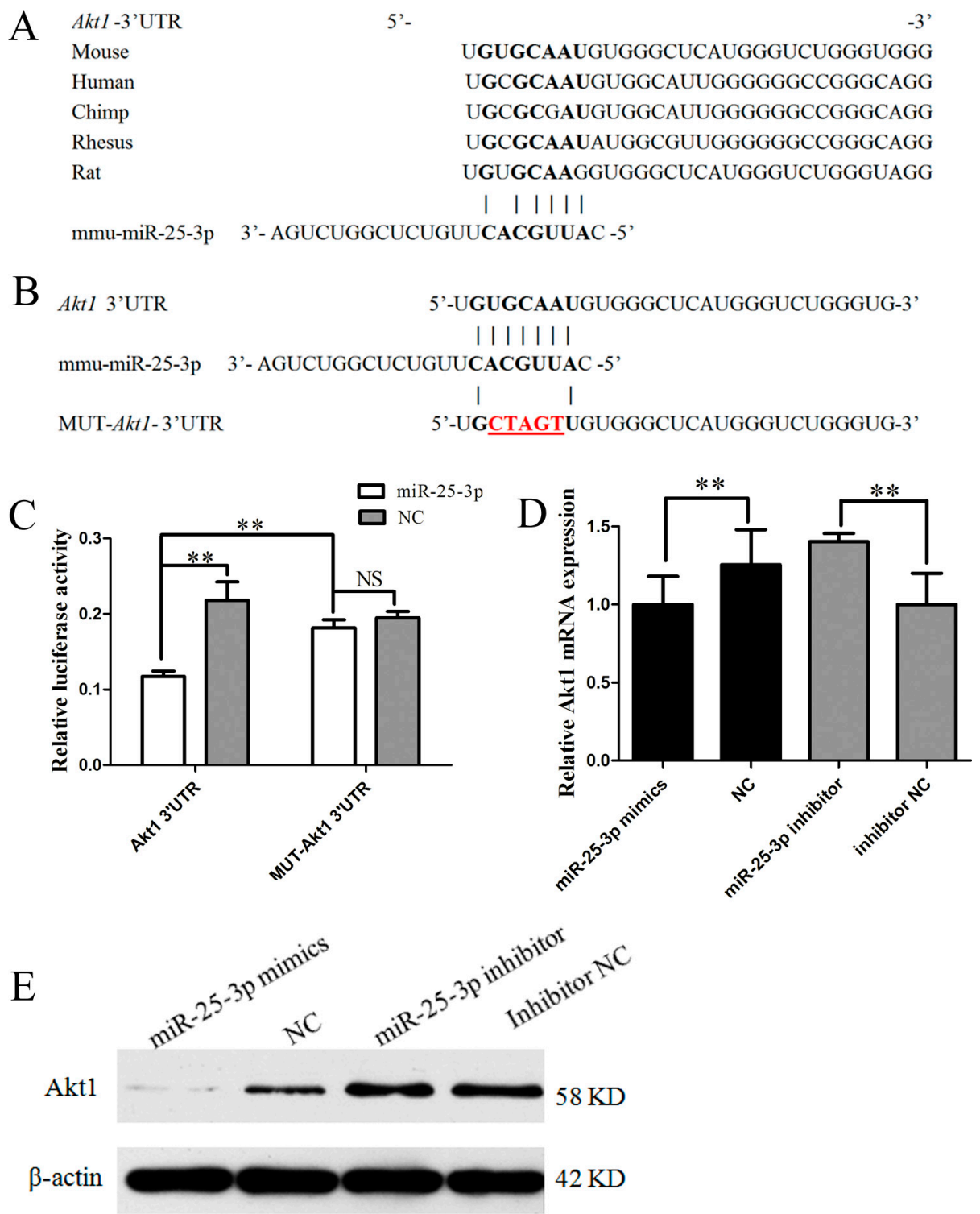

Figure 3. miR-25-3p directly targets the $3^{\prime} \mathrm{UTR}$ of $A k t 1$. (A) The sequences of miR-25-3p target elements in the $A k t 13^{\prime}$ UTR were relatively conserved in many mammals. These sequences were obtained from TargetScan. (B) Site-directed mutagenesis of the miR-25-3p target site in the Akt1 3'UTR; mutated bases shown in red. (C) Dual luciferase reporter assay. The $A k t 13^{\prime} \mathrm{UTR} /$ mutant plasmid was cotransfected with miR-25-3p mimics/NC, respectively, into growing $\mathrm{C} 2 \mathrm{C} 12$ cells; dual luciferase activities were measured from cell lysates ( $24 \mathrm{~h}$ after transfection). miR-25-3p mimics/NC or inhibitors/NC were respectively transfected into growing $\mathrm{C} 2 \mathrm{C} 12$ cells. After $48 \mathrm{~h}, A k t 1$ expression was detected by qRT-PCR (D) and Western blotting (E). NC = negative control (miR-239b-5p of caenorhabditis elegans). $\beta$-actin served as the loading control. Data were presented as means $\pm \operatorname{SD}(n \geq 3) .{ }^{* *} p<0.01$; NS, not significant. 


\subsection{Identification and Characterization of the Mouse miR-25-3p Promoter}

To further identify the promoter region and regulatory elements of mouse miR-25-3p, we used luciferase assays to analyze a series of deletions in the potential promoter region, as predicted by neural network promoter prediction (NNPP) online software (Figure 4A).The plasmids containing the various lengths of the miR-25-3p promoter were transiently transfected into growing $\mathrm{BHK}$ and $\mathrm{C} 2 \mathrm{C} 12$ cells. Analyses of luciferase activity revealed that miR-25-3p-P9 $(-119 /+144)$ showed the greatest transcriptional activity, and the longer fragment showed lower transcriptional activity (Figure 4B), indicating that the region from -1870 to -119 contains one or more cis-acting elements that can repress miR-25-3p expression. The result demonstrates that this $263 \mathrm{bp}$-long sequence was the core promoter of mouse miR-25-3p.

\subsection{The Transcription Factor AP-2 $\alpha$ Binds to the Core Promoter of Mouse miR-25-3p}

To further search the transcription factors that bind to the core promoter of mouse miR-25-3p, AliBaba 2.1 and Genomatix software programs were utilized to analyze the putative transcription factors. As shown in Figure S2, AP- $2 \alpha$ was found to be able to bind to the core promoter of mouse miR-25-3p. To examine whether AP- $2 \alpha$ influences the activity of the mouse miR-25-3p promoter, an AP- $2 \alpha$ overexpression plasmid (pc-AP- $2 \alpha$ ) was generated and cotransfected with the miR-25-3p-P9 plasmid into growing $\mathrm{C} 2 \mathrm{C} 12$ cells. Twenty-four hours after transfection, analyses of luciferase activity showed that pc-AP-2 $\alpha$ significantly increased miR-25-3p promoter transcriptional activity (Figure 4 C).

To determine the functional importance of the AP- $2 \alpha$ binding site, we mutated the AP- $2 \alpha$ binding site at -109 to -102 , by using the wild-type miR-25-3p-P9 plasmid as the template. The mutant was constructed and transfected into growing C2C12 cells. As shown in Figure 4D, the luciferase activity of the mutant was significantly decreased as compared with the wild-type miR-25-3p-P9 construct. These results indicated that transcription factor AP- $2 \alpha$ may induce transcriptional activity by directly binding to the core promoter of mouse miR-25-3p.

To further verify whether transcription factor AP- $2 \alpha$ binds to the core promoter of mouse miR-25-3p, ChIP was performed in growing C2C12 cells. Chromatin was immunoprecipitated using the AP- $2 \alpha$ antibody, and PCR amplification was performed, using the DNA fragment of the expected size as a template. The ChIP-Q-PCR assay showed that AP-2 $\alpha$ interacted with the miR-25-3p promoter within the binding site (Figure $4 \mathrm{E}$ ). These results confirmed that the transcription factor AP-2 $\alpha$ is capable of binding to the AP- $2 \alpha$ binding site in the mouse miR-25-3p promoter region, and induces miR-25-3p transcription.

\subsection{AP-2 $\alpha$ Regulates miR-25-3p and Akt1 Expression}

Because $A k t 1$ was identified as a direct target of miR-25-3p, and the transcription factor AP- $2 \alpha$ could upregulate miR-25-3p transcription, the effect of AP-2 $\alpha$ on Akt1 expression was further appraised by the overexpression or knockdown of AP- $2 \alpha$ in growing C2C12 cells. As AP- $2 \alpha$ mRNA expression was significantly decreased by doublestranded short interfering AP-2 $\alpha$ RNA ( si-AP-2 $\alpha-1$ ) and si-AP- $2 \alpha-2$, and the inhibitory effect of si-AP- $2 \alpha-2$ was greater than that of si-AP- $2 \alpha-1$ (Figure S3), si-AP- $2 \alpha-2$ was chosen for subsequent experiments. pc-AP- $2 \alpha$ or si-AP- $2 \alpha$ was transfected into growing $\mathrm{C} 2 \mathrm{C} 12$ cells, respectively. Fourty-eight hours after transfection, RNA and protein were isolated. The overexpression of AP-2 $\alpha$ significantly increased miR-25-3p expression, while the knockdown of AP- $2 \alpha$ resulted in the significant suppression of miR-25-3p expression (Figure 5A). Conversely, the mRNA and protein expression of Akt1 were significantly suppressed by AP- $2 \alpha$ overexpression, and were increased by si-AP- $2 \alpha$ (Figure $5 \mathrm{~B}-\mathrm{D}$ ). These results indicate that AP- $2 \alpha$ activated mature miR-25 expression, and downregulated the expression of $A k t 1$. 


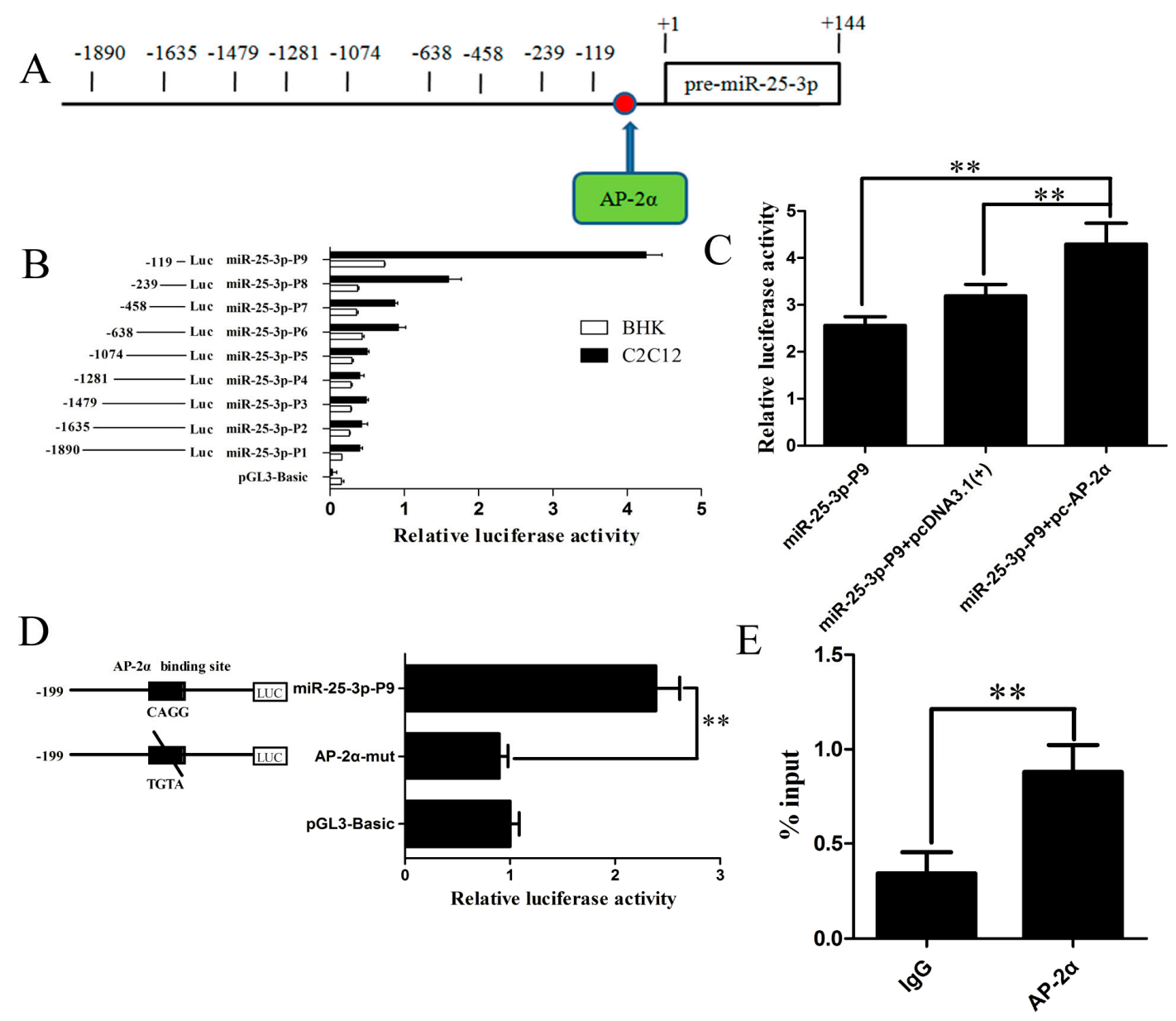

Figure 4. Transcription factor AP-2 $\alpha$ binds to the miR-25-3p promoter region. (A) Schematic diagram of the AP- $2 \alpha$ binding site (arrow, red dot) in the miR-25-3p promoter. The first nucleotide of pre-miR-25-3p was assigned as +1 , and the other nucleotides were numbered relative to it. (B) A series of progressive deletion mutants were transfected into growing $\mathrm{BHK}$ and $\mathrm{C} 2 \mathrm{C} 12$ cells, and the promoter activities were analyzed by dual luciferase activity assay. (C) miR-25-3p-P9 reporter constructs were cotransfected with pc-AP- $2 \alpha$ into growing C2C12 cells. Dual luciferase activity was measured $24 \mathrm{~h}$ after transfection. Overexpression of AP- $2 \alpha$ upregulated miR-25-3p promoter luciferase activity. pcDNA-3.1(+) was used as a control. (D) Site-directed mutagenesis of the AP- $2 \alpha$ binding site (CAGG into TGTA) in the miR-25-3p promoter region resulted in the miR-25-3p-P9 luciferase activity being reduced. Data were expressed as the ratio of relative activity, normalized to $\mathrm{pRL}-\mathrm{TK}$, and presented as means $\pm \mathrm{SD}$ $(n \geq 3)$. (E) Binding of AP-2 $\alpha$ to the miR-25-3p promoter region was analyzed by chromatin immunoprecipitation (ChIP). DNA isolated from immunoprecipitated materials was amplified using qRT-PCR. Normal mouse IgG was used as the negative control. Data were normalized by total chromatin (input) and presented as means $\pm \operatorname{SD}(n=3) ;{ }^{* *} p<0.01$. 
A

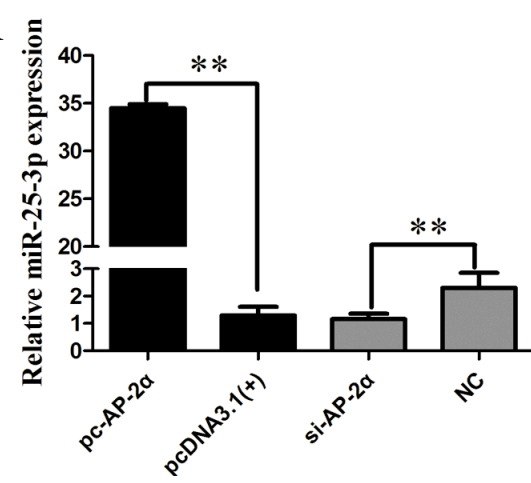

$\mathrm{B}$

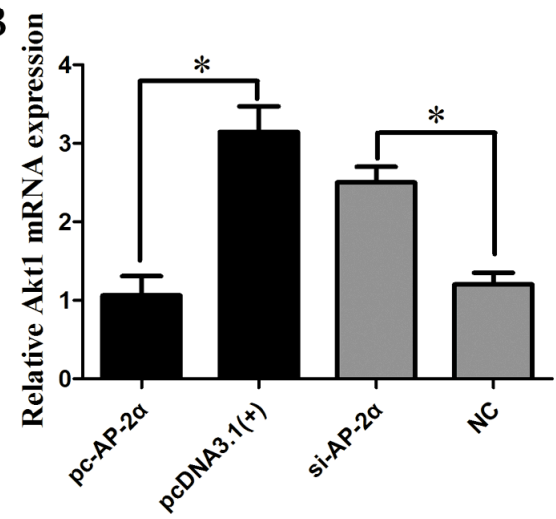

$\mathrm{C}$

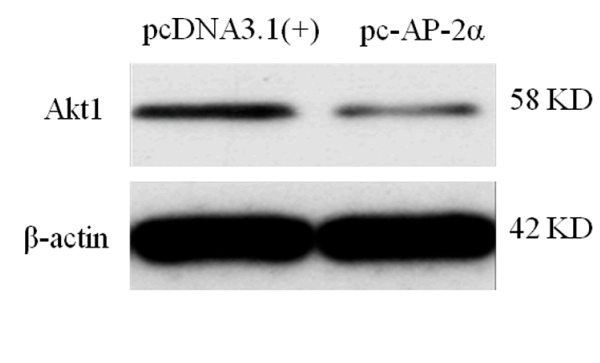

$\mathrm{D}$

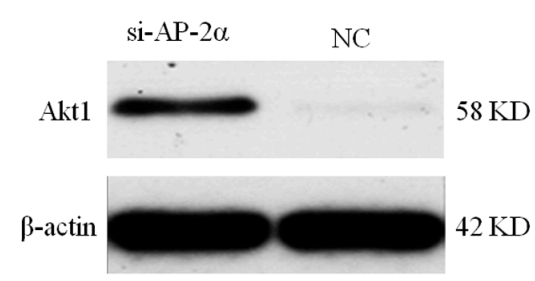

Figure 5. The effects of AP- $2 \alpha$ on the expression of miR-25-3p and Akt1. The eukaryotic expression plasmid pc-AP- $2 \alpha$ or si-AP- $2 \alpha$ was transfected into growing $\mathrm{C} 2 \mathrm{C} 12$ cells. After $48 \mathrm{~h}$, the expression of miR-25-3p and Akt1 was detected by qRT-PCR and Western blotting. (A) The expression of miR-25-3p was detected by qRT-PCR. (B) The mRNA expression of $A k t 1$ was detected by qRT-PCR. Data were presented as means $\pm \mathrm{SD}(n=3) ;{ }^{*} p<0.05 ;{ }^{* *} p<0.01$. (C) The protein expression of Akt1 was detected by Western blotting after pc-AP-2 $\alpha$ transfection. (D) The protein expression of Akt1 was detected by Western blotting after si-AP- $2 \alpha$ transfection. $\beta$-actin served as the loading control.

\section{Discussion}

Increasing evidence shows that miR-25, a member of the miR-106b-25 cluster, is involved in many biological processes. For instance, miR-25 inhibits human gastric adenocarcinoma cell apoptosis [15], promotes glioblastoma cell proliferation and invasion [16], and regulates human ovarian cancer apoptosis [17]. The miR-106b-25 cluster regulates adult neural stem/progenitor cell proliferation, migration, and differentiation [18,19]. miR-25 plays an important role in heart disease [11,12] and diabetic kidney disease [13]. In addition, numerous studies have demonstrated that miRNAs are implicated in metabolism [20-23]. However, miR-25 has not been functionally related to metabolism until now.

In this study, miR-25 was identified as a novel regulator of metabolism. The gain-of-function and loss-of-function assays showed that miR-25-3p inhibited the expression of PI3K and reduced levels of triglyceride (TG), while levels of ATP and ROS were increased. PI3K has been implicated in insulin-regulated glucose metabolism [24], and PI3K signaling has a role in many cellular processes, such as metabolic control, immunity, and cardiovascular homeostasis [25-27]. It is well-known that triglycerides (TG) are a component of lipids, and participate in lipid metabolism. ATP is the most direct source of energy in an organism, and takes part in many metabolic processes. ROS, a class of single electron radicals of oxygen, comprise superoxide anions $\left(\mathrm{O}_{2}{ }^{-}\right)$, hydrogen peroxide $\left(\mathrm{H}_{2} \mathrm{O}_{2}\right)$, and hydroxyl radicals ( $\cdot \mathrm{OH})$ [28], and are closely related to adipogenesis and myogenesis [28-31]. These data indicate that miR-25-3p indeed participates in metabolism in mice. 
To further understand the molecular mechanism by which miR-25-3p regulates metabolism, we searched for potential target genes of miR-25-3p via TargetScan. Fortunately, the 3'UTR of Akt 1 contained a 7 nucleotides perfect match site complementary to the miR-25-3p seed region (Figure 3B). The serine-threonine kinase ATK, also known as protein kinase B (PKB), is an important effector for PI3K signaling as initiated by numerous growth factors and hormones [32]. Akt can control glucose uptake by regulating GLUT4 in cells, thereby reducing blood sugar and promoting glycogen synthesis [32-34]. Akt usually promotes glycogen synthase kinase-3 alpha (GSK3 $\alpha$ ) phosphorylation and inhibits its activity [35], and then activates glycogen synthesis [36]. A previous study has demonstrated that overexpression of miR-25-3p downregulates Akt expression and inactivates Akt phosphorylation in the tongue squamous cell carcinoma cell line Tca8113 [37]. Consequently, we deduced that the role of miR-25-3p in metabolism may arise from its inhibition of $A k t 1$. First, the dual luciferase reporter assay demonstrated that $A k t 1$ was a direct target of miR-25-3p, shown by the steady decrease luciferase activity of the pmirGLO-Akt1-wt vector; but not the mutant form (Figure 3C). Meanwhile, qRT-PCR and Western blotting results showed that the expression of Akt1 was inhibited by the miR-25-3p mimics, and that this inhibition was reversed by the miR-25-3p inhibitors (Figure 3D,E). These results suggested that the effect of miR-25-3p in metabolism was due, at least in part, to the suppression of $A k t 1$.

An increasing number of studies have shown that transcription factors are capable of binding to miRNA promoter elements and modulating miRNA transcription [38-40]. Therefore, we analyzed the transcriptional mechanism of miR-25-3p in this study. Nine fragments of $5^{\prime}$-flanking sequences of mouse miR-25-3p were isolated. Subsequently, a series of experiments, including dual luciferase, site-directed mutagenesis, and ChIP assays, confirmed that AP- $2 \alpha$ bound to the miR-25-3p promoter region and promoted its transcription activity (Figure 4). Moreover, qRT-PCR and Western blotting results showed that overexpression of AP- $2 \alpha$ resulted in the upregulation of miR-25-3p and downregulation of $A k t 1$, and that the knockdown of AP-2 $\alpha$ reversed these results (Figure 5).

The AP- 2 family of transcription factors consists of five members, in humans and mice: AP- $2 \alpha$, $\mathrm{AP}-2 \beta, \mathrm{AP}-2 \gamma, \mathrm{AP}-2 \delta$, and AP- $2 \varepsilon$; which play important roles in several cellular processes, such as apoptosis, migration, and differentiation [41,42]. AP-2 $\alpha$ was first identified by its ability to bind to the enhancer regions of SV40 and human metallothionein IIA [43]. Subsequently, numerous studies have demonstrated that AP- $2 \alpha$ can regulate gene expression. For instance, AP- $2 \alpha$ binding to the $C / E B P \alpha$ promoter results in decreased C/EBP $\alpha$ expression [44], and AP- $2 \alpha$ can bind to the TACE promoter and decrease its expression in dendritic cells [45]. Furthermore, Qiao et al. [46] reported that there was an AP- $2 \alpha$ binding site in the DEK core promoter, and overexpression of AP- $2 \alpha$ upregulated $D E K$ expression. In this study, we identified that AP- $2 \alpha$ binds to the miR-25-3p promoter region and promotes its transcription activity.

In conclusion, our results demonstrate that miR-25-3p acts as a positive regulator of the metabolism of growing $\mathrm{C} 2 \mathrm{C} 12$ cells, by affecting Akt1 gene expression through directly binding to its $3^{\prime}$ UTR. Moreover, the transcription factor AP- $2 \alpha$ is able to bind to the core promoter of mouse miR-25-3p, activating mature miR-25 expression and downregulating the expression of Akt1 (Figure 6). 


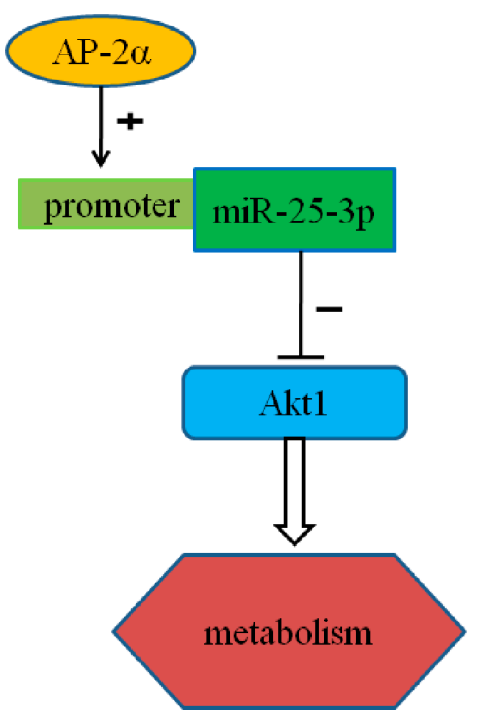

Figure 6. Representation of the proposed mechanism. miR-25-3p is regulated by transcription factor $\mathrm{AP}-2 \alpha$, and contributes to $\mathrm{C} 2 \mathrm{C} 12$ metabolism by targeting $A k t 1$. The arrow-head and "+" represent activation while the blunt-head and "-" represent suppression.

\section{Materials and Methods}

\section{1. miRNA, Small RNA Oligonucleotide Synthesis, and Plasmid Construction}

The miR-25-3p oligonucleotides (miR-25-3p mimics, NC, miR-25-3p inhibitors, and inhibitor-NC) and double-stranded short interfering RNAs (siRNAs) targeting AP- $2 \alpha$ were designed and synthesized by RiboBio (Guangzhou, China).The oligonucleotides are listed in Table S1.

To construct the AP- $2 \alpha$ overexpression vector pc-AP- $2 \alpha$, the AP- $2 \alpha$ coding sequence (1314 bp) was amplified from mouse $\mathrm{C} 2 \mathrm{C} 12$ cells cDNA using the following primers: forward: $5^{\prime}$-CCC AAGCTTGCCACCATGCTTTGGAAACTGACGGA-3'; reverse: 5'-CCGCTCGAGTCACTTTCTGTG TTTCTCTT- $3^{\prime}$. The PCR product was subcloned into the HindIII/XhoI sites of the pcDNA3.1(+) vector (Invitrogen, Carlsbad, CA, USA).

The potential target site of miR-25-3p, localized in the 3'UTR of Akt1 mRNA, was predicted by TargetScan (Available online: http:/ / www.targetscan.org/) [47]. The Akt1 3'UTR was amplified from C2C12 cell cDNA and inserted into the PmeI/XhoI sites of the pmirGLO vector (Promega, Madison, WI, USA). Point mutations in the seed region of the predicted miR-25-3p sites within the $3^{\prime} \mathrm{UTR}$ of $A k t 1$ were generated using overlap-extension PCR [48]. The corresponding primers are listed in Table S2.

The potential promoter regions of miR-25-3p was predicted by using the neural network promoter prediction (NNPP) software (Available online: http:/ / www.fruitfly.org/seq_tools/promoter.html) [49]. Nine miR-25-3p promoter deletion fragments were amplified from the mouse genome via PCR with the primers listed in Table S3.The nine purified PCR products were ligated into the KpnI/HindIII sites of the pGL3-Basic vector (Promega). AliBaba2.1 (Available online: http:/ / www.gene-regulation.com/) [50] and MatInspector (Available online: http://www.genomatix.de/online_help/help_matinspector/ matinspector_help.html) [49] were used to predict the potential transcription factor binding sites. The AP- $2 \alpha$ transcription factor binding sites of the miR-25-3p promoter region were also mutated by overlap-extension PCR. The primers are provided in Table S3.

\subsection{Cell Culture and Luciferase Reporter Assays}

C2C12 (mouse muscle myoblast) and BHK (baby hamster kidney) cells were cultured in DMEM (Gibco, Gaithersburg, MD, USA) containing 10\% fetal bovine serum (FBS) (Gibco) at 5\% $\mathrm{CO}_{2}$ and $37^{\circ} \mathrm{C}$. 
For luciferase reporter assays, growing $\mathrm{C} 2 \mathrm{C} 12$ or BHK cells were seeded in 48-well plates. After 12-16 h, the plated cells were transfected with a recombinant plasmid using Lipofectamine 2000 (Invitrogen). To verify the miR-25-3p targeting Akt1 3'UTR, $1 \mu \mathrm{L}$ miR-25-3p mimics/NC was cotransfected with $0.1 \mu \mathrm{g} A k t 13^{\prime} \mathrm{UTR} /$ mutant plasmid into C2C12 cells. For the miR-25-3p promoter luciferase reporter assay, $0.4 \mu \mathrm{g}$ pGL3-Basic or recombinant plasmids and $20 \mathrm{ng}$ pRL-TK vector were transfected. For cotransfection luciferase assays, each well contained 0.2 $\mu$ g pGL3-(Basic, miR-25-3p-P9 and AP-2 $\alpha$-mut), $20 \mathrm{ng}$ pRL-TK, and $0.2 \mu \mathrm{g}$ pc-AP-2 $\alpha$. Empty pcDNA-3.1(+) cotransfected with pGL3-(Basic, miR-25-3p-P9 and AP-2 $\alpha$-mut) was used as the control. After $24 \mathrm{~h}$ of incubation, luciferase activity was measured using a PerkinElmer 2030 Multilabel Reader (PerkinElmer, Norwalk, CT, USA).

\subsection{Triglyceride Content, ATP, and Reactive Oxygen Species (ROS) Assays}

For detecting the concentrations of triglyceride (TG), ATP, and ROS, growing $\mathrm{C} 2 \mathrm{C} 12$ cells were seeded in 24-well plates the day before transfection. miR-25-3p mimic, NC, miR-25-3p inhibitor, and inhibitor-NC were transfected into confluent $(\sim 80 \%)$ cells, respectively, at a concentration of $12 \mathrm{nM}$ with Lipofectamine 2000 (Invitrogen). After 24-48 h, the concentrations of TG and ATP in the lysates of cells were measured with commercial kits (Applygen (Beijing, China) and Beyotime (Shanghai, China), respectively) following the manufacturer's instructions, and normalized to the protein content ( $\mu \mathrm{mol} / \mathrm{mg}$ protein) using the BCA assay kit (Thermo Scientific, Waltham, MA, USA). ROS were measured using the reactive oxygen species assay kit (Beyotime) following the manufacturer's protocol.

\subsection{Chromatin Immunoprecipitation (ChIP)}

ChIP assays were performed to assess the binding of endogenous AP-2 $\alpha$ to the miR-25-3p promoter in C2C12 cells using the EZ-ChIPTM Kit (Millipore, Boston, MA, USA), following a previously described method [49]. Precleared chromatin was incubated with the AP-2 $\alpha$ antibody (Santa Cruz Biotechnology, Dallas, TX, USA) or normal mouse IgG (Millipore) antibodies (control) overnight at $4{ }^{\circ} \mathrm{C}$. Purified DNA from the samples and the input controls were analyzed for the presence of miR-25-3p promoter sequences containing putative AP- $2 \alpha$ response elements using qPCR. The primers used here are listed in Table S4.

\subsection{RNA Isolation and $q R T-P C R$}

For quantifying the mRNA expression of genes, growing $\mathrm{C} 2 \mathrm{C} 12$ cells were seeded in 6-well plates. miR-25-3p mimic, NC, miR-25-3p inhibitor, inhibitor-NC, si-AP-2 $\alpha$, and NC were transfected into confluent $(\sim 80 \%)$ cells, respectively, at a concentration of $50 \mathrm{nM}$ with Lipofectamine 2000 (Invitrogen). After 48 h, total RNA was isolated using a HP Total RNA Kit (Omega, Norcross, GA, USA) according to the manufacturer's protocol. The cDNA was synthesized using a PrimeScript ${ }^{\mathrm{TM}}$ RT reagent Kit with gDNA Eraser (Takara, Osaka, Japan) according to the manufacturer's protocol. The qRT-PCR was performed in triplicate with iQSYBR green Supermix (Bio-Rad, Hercules, CA, USA) in a LightCycler 480 Realtime PCR machine (Roche, Basel, Switzerland). The mRNA levels of target genes were reported relative to those of the house keeping gene $\beta$-actin by using the $2^{-\Delta \Delta C t}$ method. The qRT-PCR primers are listed in Table S5.

\subsection{Protein Isolation and Western Blotting}

For detecting the protein expression of PI3K and Akt1, growing $\mathrm{C} 2 \mathrm{C} 12$ cells were seeded in6-well plates. miR-25-3p mimic, NC, miR-25-3p inhibitor, inhibitor-NC, si-AP-2 $\alpha$, and NC were transfected into confluent $(\sim 80 \%)$ cells, respectively, at a concentration of $50 \mathrm{nM}$ with Lipofectamine 2000 (Invitrogen). After $48 \mathrm{~h}$, total protein was isolated using RIPA Lysis Buffer (Beyotime). The cells were washed briefly with cold phosphate-buffered saline (PBS), $150 \mu$ L RIPA Lysis Buffer (containing $1 \mathrm{mM}$ PMSF) was added, incubated for $1 \mathrm{~min}$ at room temperature, and then centrifuged at $12,000 \times g$ for $5 \mathrm{~min}$. The supernatant extract was used for Western blot analysis. 
Western blot analysis was performed to analyze the expression levels of Akt1 (Affinity Biosciences, Cincinnati, OH, USA) andPI3K (Abclonal, Wuhan, China) according to the methods of Huang et al. [47]. $\beta$-actin (Santa Cruz Biotechnology) served as the loading control.

\subsection{Statistical Analysis}

All the results are presented as the means \pm SD. Student's $t$-test was used for statistical comparisons. A $p$ value of $<0.05$ was considered to be statistically significant. ${ }^{* *} p<0.01$; ${ }^{*} p<0.05$; NS, not significant.

Supplementary Materials: The following are available online at www.mdpi.com/1422-0067/19/3/773/s1.

Acknowledgments: This research wassupported by the China Postdoctoral Science Foundation (2017M610465), the Open Project of Key Laboratory of Animal Embryo Engineering and Molecular Breeding of Hubei Province (KLAEMB201602),the Postdoctoral Innovation Post of Hubei Province (2016), the National Natural Science Foundationof China (31472075, 31402051 and 31501932), and Natural Science Foundation of Hubei Province key projects of technical innovation (2016ABA117).

Author Contributions: Mingxin Chen and Siwen Jiang conceived and supervised the study; Feng Zhang and Kun Chen designed experiments; Tingting Kang and Qianhui Zeng performed experiments; Hu Tao and Qi Xiong analysed data; Feng Zhang wrote the manuscript; Yang Liu made manuscript revisions.

Conflicts of Interest: The authors declare no conflict of interest.

\section{References}

1. Bartel, D.P. MicroRNAs: Genomics, biogenesis, mechanism, and function. Cell 2004, 116, 281-297. [CrossRef]

2. Malan-Muller, S.; Hemmings, S.M.; Seedat, S. Big effects of small RNAs: A review of microRNAs in anxiety. Mol. Neurobiol. 2013, 47, 726-739. [CrossRef] [PubMed]

3. Carthew, R.; Sontheimer, E. Origins and Mechanisms of miRNAs and siRNAs. Cell 2009, 136, 642-655. [CrossRef] [PubMed]

4. Ning, B.; Gao, L.; Liu, R.; Liu, Y.; Zhang, N.; Chen, Z. microRNAs in spinal cord injury: Potential roles and therapeutic implications. Int. J. Biol. Sci. 2014, 10, 997-1006. [CrossRef] [PubMed]

5. Deshmukh, A.; Murgia, M.; Nagaraj, N.; Treebak, J.; Cox, J.; Mann, M. Deep proteomics of mouse skeletal muscle enables quantitation of protein isoforms, metabolic pathways, and transcription factors. Mol. Cell Proteom. 2015, 14, 841-853. [CrossRef] [PubMed]

6. Li, M.; Song, Q.; Li, H.; Lou, Y.; Wang, L. Correction: Circulating miR-25-3p and miR-451a May Be Potential Biomarkers for the Diagnosis of Papillary Thyroid Carcinoma. PLoS ONE 2015, 10, e0135549. [CrossRef] [PubMed]

7. Nishida, N.; Nagahara, M.; Sato, T.; Mimori, K.; Sudo, T.; Tanaka, F.; Shibata, K.; Ishii, H.; Sugihara, K.; Doki, Y.; et al. Microarray analysis of colorectal cancer stromal tissue reveals upregulation of two oncogenic miRNA clusters. Clin. Cancer Res. 2012, 18, 3054-3070. [CrossRef] [PubMed]

8. Razumilava, N.; Bronk, S.F.; Smoot, R.L.; Fingas, C.D.; Werneburg, N.W.; Roberts, L.R.; Mott, J.L. miR-25 targets TNF-related apoptosis inducing ligand (TRAIL) death receptor-4 and promotes apoptosis resistance in cholangiocarcinoma. Hepatology 2012, 55, 465-475. [CrossRef] [PubMed]

9. Wang, X.; Meng, X.; Li, H.; Liu, W.; Shen, S.; Gao, Z. MicroRNA-25 expression level is an independent prognostic factor in epithelial ovarian cancer. Clin. Transl. Oncol. 2014, 16, 954-958. [CrossRef] [PubMed]

10. Zhao, H.; Wang, Y.; Yang, L.; Jiang, R.; Li, W. MiR-25 promotes gastric cancer cells growth and motility by targeting RECK. Mol. Cell. Biochem. 2014, 385, 207-213. [CrossRef] [PubMed]

11. Wahlquist, C.; Jeong, D.; Rojas-Muñoz, A.; Kho, C.; Lee, A.; Mitsuyama, S.; van Mil, A.; Park, W.; Sluijter, J.; Doevendans, P.; et al. Inhibition of miR-25 improves cardiac contractility in the failing heart. Nature 2014, 508, 531-535. [CrossRef] [PubMed]

12. Pan, L.; Huang, B.; Ma, X.; Wang, S.; Feng, J.; Lv, F.; Liu, Y.; Liu, Y.; Li, C.; Liang, D.; et al. MiR-25 protects cardiomyocytes against oxidative damage by targeting the mitochondrial calcium uniporter. Int. J. Mol. Sci. 2015, 16, 5420-5433. [CrossRef] [PubMed] 
13. Liu, Y.; Li, H.; Liu, J.; Han, P.; Li, X.; Bai, H.; Zhang, C.; Sun, X.; Teng, Y.; Zhang, Y.; et al. Variations in MicroRNA-25 Expression Influence the Severity of Diabetic Kidney Disease. J. Am. Soc. Nephrol. 2017, 28, 3627-3638. [CrossRef] [PubMed]

14. Sievers, F.; Higgins, D. Clustal Omega, accurate alignment of very large numbers of sequences. Methods Mol. Biol. 2014, 1079, 105-116. [PubMed]

15. Zhang, Y.; Peng, Z.; Zhao, Y.; Chen, L. microRNA-25 Inhibits Cell Apoptosis of Human Gastric Adenocarcinoma Cell Line AGS via Regulating CCNE1 and MYC. Med. Sci. Monit. 2016, 22, 1415-1420. [CrossRef] [PubMed]

16. Peng, G.; Yuan, X.; Yuan, J.; Liu, Q.; Dai, M.; Shen, C.; Ma, J.; Liao, Y.; Jiang, W. miR-25 promotes glioblastoma cell proliferation and invasion by directly targeting NEFL. Mol. Cell. Biochem. 2015, 409, 103-111. [CrossRef] [PubMed]

17. Zhang, H.; Zuo, Z.; Lu, X.; Wang, L.; Wang, H.; Zhu, Z. miR-25 regulates apoptosis by targeting Bim in human ovarian cancer. Oncol. Rep. 2012, 27, 594-598. [PubMed]

18. Brett, J.O.; Renault, V.M.; Rafalski, V.A.; Webb, A.E.; Brunet, A. The microRNA cluster miR-106b 25 regulates adult neural stem/progenitor cell proliferation and neuronal differentiation. Aging 2011, 3, 108-124. [CrossRef] [PubMed]

19. Yu, Y.; Lu, X.; Ding, F. microRNA regulatory mechanism by which PLLA aligned nanofibers influence PC12 cell differentiation. J. Neural Eng. 2015, 12, 046010. [CrossRef] [PubMed]

20. Rottiers, V.; Näär, A. MicroRNAs in metabolism and metabolic disorders. Nat. Rev. Mol. Cell Biol. 2012, 13, 239-250. [CrossRef] [PubMed]

21. Guo, N.; Zhang, J.; Wu, J.; Xu, Y. Isoflurane promotes glucose metabolism through up-regulation of miR-21 and suppresses mitochondrial oxidative phosphorylation in ovarian cancer cells. Biosci. Rep. 2017, 37. [CrossRef] [PubMed]

22. Ling, L.; Kokoza, V.; Zhang, C.; Aksoy, E.; Raikhel, A. MicroRNA-277 targets insulin-like peptides 7 and 8 to control lipid metabolism and reproduction in Aedes aegypti mosquitoes. Proc. Natl. Acad. Sci. USA 2017, 114, E8017-E8024. [CrossRef] [PubMed]

23. Gao, P.; Tchernyshyov, I.; Chang, T.; Lee, Y.; Kita, K.; Ochi, T.; Zeller, K.; De Marzo, A.; van Eyk, J.; Mendell, J.; et al. c-Myc suppression of miR-23a/b enhances mitochondrial glutaminase expression and glutamine metabolism. Nature 2009, 458, 762-765. [CrossRef] [PubMed]

24. Pessin, J.E.; Saltiel, A.R. Signaling pathways in insulin action: Molecular targets of insulin resistance. J. Clin. Investig. 2000, 106, 165-169. [CrossRef] [PubMed]

25. Vanhaesebroeck, B.; Guillermet-Guibert, J.; Graupera, M.; Bilanges, B. The emerging mechanisms of isoform-specific PI3K signalling. Nat. Rev. Mol. Cell Biol. 2010, 11, 329-341. [CrossRef] [PubMed]

26. Courtnay, R.; Ngo, D.; Malik, N.; Ververis, K.; Tortorella, S.; Karagiannis, T. Cancer metabolism and the Warburg effect: The role of HIF-1 and PI3K. Mol. Biol. Rep. 2015, 42, 841-851. [CrossRef] [PubMed]

27. Knight, Z.; Shokat, K. Chemically targeting the PI3K family. Biochem. Soc. Trans. 2007, 35 Pt 2, $245-249$. [CrossRef] [PubMed]

28. Carrière, A.; Fernandez, Y.; Rigoulet, M.; Pénicaud, L.; Casteilla, L. Inhibition of preadipocyte proliferation by mitochondrial reactive oxygen species. FEBS Lett. 2003, 550, 163-167. [CrossRef]

29. Carrière, A.; Carmona, M.; Fernandez, Y.; Rigoulet, M.; Wenger, R.; Pénicaud, L.; Casteilla, L. Mitochondrial reactive oxygen species control the transcription factor CHOP-10/GADD153 and adipocyte differentiation: A mechanism for hypoxia-dependent effect. J. Biol. Chem. 2004, 279, 40462-40469. [CrossRef] [PubMed]

30. Ding, Y.; Choi, K.; Kim, J.; Han, X.; Piao, Y.; Jeong, J.; Choe, W.; Kang, I.; Ha, J.; Forman, H.; et al. Endogenous hydrogen peroxide regulates glutathione redox via nuclear factor erythroid 2-related factor 2 downstream of phosphatidylinositol 3-kinase during muscle differentiation. Am. J. Pathol. 2008, 172, 1529-1541. [CrossRef] [PubMed]

31. Won, H.; Lim, S.; Jang, M.; Kim, Y.; Rashid, M.; Jyothi, K.; Dashdorj, A.; Kang, I.; Ha, J.; Kim, S. Peroxiredoxin-2 upregulated by NF- $\mathrm{kB}$ attenuates oxidative stress during the differentiation of muscle-derived C2C12 cells. Antioxid. Redox Signal. 2012, 16, 245-261. [CrossRef] [PubMed]

32. Cho, H.; Thorvaldsen, J.L.; Chu, Q.; Feng, F.; Birnbaum, M.J. Akt1/PKB $\alpha$ is required for normal growth but dispensable for maintenance of glucose homeostasis in mice. J. Biol. Chem. 2001, 276, 38349-38352. [CrossRef] [PubMed] 
33. Gonzalez, E.; McGraw, T.E. The Akt kinases Isoform specificity in metabolism and cancer. Cell Cycle 2009, 8, 2502-2508. [CrossRef] [PubMed]

34. Chen, W.S.; Xu, P.-Z.; Gottlob, K.; Chen, M.-L.; Sokol, K.; Shiyanova, T.; Roninson, I.; Weng, W.; Suzuki, R.; Tobe, K.; et al. Growth retardation and increased apoptosis in mice with homozygous disruption of the akt1 gene. Genes Dev. 2001, 15, 2203-2208. [CrossRef] [PubMed]

35. Beurel, E.; Grieco, S.; Jope, R. Glycogen synthase kinase-3 (GSK3): Regulation, actions, and diseases. Pharmacol. Ther. 2015, 148, 114-131. [CrossRef] [PubMed]

36. Agius, L. Role of glycogen phosphorylase in liver glycogen metabolism. Mol. Asp. Med. 2015, 46, 34-45. [CrossRef] [PubMed]

37. Xu, J.; Yang, L.; Ma, C.; Huang, Y.; Zhu, G.; Chen, Q. MiR-25-3p attenuates the proliferation of tongue squamous cell carcinoma cell line Tca8113. Asian Pac. J. Trop. Med. 2013, 6, 743-747. [CrossRef]

38. Zheng, H.; Dong, X.; Liu, N.; Xia, W.; Zhou, L.; Chen, X.; Yang, Z.; Chen, X. Regulation and mechanism of mouse miR-130a/b in metabolism-related inflammation. Int. J. Biochem. Cell Biol. 2016, 74, 72-83. [CrossRef] [PubMed]

39. Zhu, B.; Ye, J.; Ashraf, U.; Li, Y.; Chen, H.; Song, Y.; Cao, S. Transcriptional regulation of miR-15b by c-Rel and CREB in Japanese encephalitis virus infection. Sci. Rep. 2016, 6, 22581. [CrossRef] [PubMed]

40. Bueno, M.; Gómez de Cedrón, M.; Laresgoiti, U.; Fernández-Piqueras, J.; Zubiaga, A.; Malumbres, M. Multiple E2F-induced microRNAs prevent replicative stress in response to mitogenic signaling. Mol. Cell. Biol. 2010, 30, 2983-2995. [CrossRef] [PubMed]

41. Wenke, A.; Bosserhoff, A. Roles of AP-2 transcription factors in the regulation of cartilage and skeletal development. FEBS J. 2010, 277, 894-902. [CrossRef] [PubMed]

42. Eckert, D.; Buhl, S.; Weber, S.; Jäger, R.; Schorle, H. The AP-2 family of transcription factors. Genome Biol. 2005, 6, 246. [CrossRef] [PubMed]

43. Mitchell, P.; Wang, C.; Tjian, R. Positive and negative regulation of transcription in vitro: Enhancer-binding protein AP-2 is inhibited by SV40 T antigen. Cell 1987, 50, 847-861. [CrossRef]

44. Holt, E.; Lane, M. Downregulation of repressive CUP/AP-2 isoforms during adipocyte differentiation. Biochem. Biophys. Res. Commun. 2001, 288, 752-756. [CrossRef] [PubMed]

45. Ge, L.; Vujanovic, N. Soluble TNF Regulates TACE via AP-2 $\alpha$ Transcription Factor in Mouse Dendritic Cells. J. Immunol. 2017, 198, 417-427. [CrossRef] [PubMed]

46. Qiao, M.; Li, C.; Zhang, A.; Hou, L.; Yang, J.; Hu, H. Regulation of DEK expression by AP-2 $\alpha$ and methylation level of DEK promoter in hepatocellular carcinoma. Oncol. Rep. 2016, 36, 2382-2390. [CrossRef] [PubMed]

47. Huang, C.; Geng, J.; Wei, X.; Zhang, R.; Jiang, S. MiR-144-3p regulates osteogenic differentiation and proliferation of murine mesenchymal stem cells by specifically targeting Smad4. FEBS Lett. 2016, 590, 795-807. [CrossRef] [PubMed]

48. Ho, S.N.; Hunt, H.D.; Horton, R.M.; Pullen, J.K.; Pease, L.R. Site-directed mutagenesis by overlap extension using the polymerase chain reaction. Gene 1989, 77, 51-59. [CrossRef]

49. Deng, B.; Zhang, F.; Chen, K.; Wen, J.; Huang, H.; Liu, W.; Ye, S.; Wang, L.; Yang, Y.; Gong, P.; et al. MyoD promotes porcine PPARgamma gene expression through an E-box and a MyoD-binding site in the PPARgamma promoter region. Cell Tissue Res. 2016, 365, 381-391. [CrossRef] [PubMed]

50. Wei, X.; Cheng, X.; Peng, Y.; Zheng, R.; Chai, J.; Jiang, S. STAT5a promotes the transcription of mature mmu-miR-135a in 3T3-L1 cells by binding to both miR-135a-1 and miR-135a-2 promoter elements. Int. J. Biochem. Cell Biol. 2016, 77 Pt A, 109-119. [CrossRef] [PubMed]

(C) 2018 by the authors. Licensee MDPI, Basel, Switzerland. This article is an open access article distributed under the terms and conditions of the Creative Commons Attribution (CC BY) license (http:/ / creativecommons.org/licenses/by/4.0/). 